\title{
Craniocervical Posture in Patients with Obstructive Sleep Apnea
}

\author{
Chaiane Facco Piccin ${ }^{1}$ Daniela Pozzebon ${ }^{1}$ Fabricio Scapini ${ }^{1} \quad$ Eliane Castilhos Rodrigues Corrêa ${ }^{1}$ \\ 1 Post-graduate Programa in Human Communication Disorders, \\ Universidade Federal de Santa Maria, Santa Maria, RS, Brazil \\ Int Arch Otorhinolaryngol 2016;20:189-195. \\ Address for correspondence Chaiane Facco Piccin, MSc, Universidade \\ Federal de Santa Maria - Fisioterapia, Elpídio Menezes Número 265 \\ Apto 102 Santa Maria Rio Grande do Sul 97105110, Brazil \\ (e-mail: chaiane.ufsm@gmail.com).
}

\begin{abstract}
Keywords

- obstructive sleep apnea

- apnea

- photogrammetry
\end{abstract}

\section{Introduction}

Obstructive sleep apnea (OSA) is characterized by repeated episodes of upper airway obstruction associated with its diameter reduction, thus becoming vulnerable to a greater narrowing and collapse during sleep. ${ }^{1}$ The causes of OSA include factors related to upper airway anatomy, that is, restricted airspace on mandibular retrognathism, increased tongue volume, and palatal or the adenoids extension. ${ }^{2}$ Increased body mass index (BMI) was also nominated as one of the most significant predisposing factors for sleep disorders of upper airway, due to the possibility of fat deposition in the upper airway tissue, thus reducing nasopharyngeal gauge and/ or leading to hypoventilation. ${ }^{3}$ One study showed that in $56 \%$ of individuals with OSA, non-anatomical factors such as decreased responsiveness of the genioglossus, low threshold of excitement, and respiratory control instability, play an important role in the upper airway collapse. ${ }^{4}$

Acute effects of apnea and hypopnea include repeated episodes of oxygen desaturation, negative intrathoracic pressure, central nervous system awakenings, and excessive daytime sleepiness. ${ }^{5}$ Other effects of OSA can contribute to the disruption of memory reorganization and the development of mental disorders. ${ }^{6}$ received

December 10, 2015

accepted

April 18, 2016

published online

June 25, 2016
DOI http://dx.doi.org/

10.1055/s-0036-1584295. ISSN $1809-9777$.
Copyright $\odot 2016$ by Thieme Publicações License terms Ltda, Rio de Janeiro, Brazil 
Craniocervical posture is related to the stomatognathic system based on the concept of Craniocervicomandibular System, which defines the morpho-functional unit comprising the head, neck, and jaw. ${ }^{7}$ A study shows that sleep disorders could be due to an incorrect head posture of OSA subjects who are prone to greater craniocervical extension with a forward head posture. ${ }^{4}$

Cephalometric analysis is considered as an important diagnostic method, which investigates craniofacial features ${ }^{8}$ predisposing to OSA, such as posterior pharyngeal space, tongue length, and hyoid bone position. ${ }^{3,9}$ Moreover, it can be used to verify the correlation of anatomical changes and the severity of OSA, ${ }^{10}$ and to identify obstruction locations, assisting the choice of the most appropriate treatment. ${ }^{11}$ This technique is useful in assessing the upper airway morphology because, besides its low cost, it is readily available in most hospitals and radiology centers. ${ }^{11}$

The airway dimensions and structures seem to be affected by head posture and inclination and body position when evaluated by Cephalometry. ${ }^{12-14}$ When the OSA subject is awake and moves from upright to supine position, he maintains the upright tongue posture to protect against the upper airway collapse secondary to the increased gravitational load on the tongue. ${ }^{13}$ However, another study analyzed OSA and snoring subjects, demonstrating that the linear cephalometric measurements of the airway taken with conscious patients in the supine position did not differ from the corresponding measurements obtained with the patient in upright position. ${ }^{14}$

For the assessment of head posture, photogrammetry is a simple, easy, and objective analysis technique, showing good reliability. ${ }^{15}$ However, no studies have been conducted using this method for verifying the craniocervical posture in OSA patients.

This study aimed to verify the craniofacial characteristics and craniocervical posture of OSA patients and healthy subjects and to determine the possible relations with the apnea/ hypopnea index (AHI) in OSA subjects.

\section{Method}

This case-control study was approved by the Research Ethics Committee of Universidade Federal de Santa Maria (UFSM), under the CAAE number 33665714.0.0000.5346, according to the Resolution 466/2012 of the National Health Council. The participants were divided into two groups: control group without sleep apnea (CG) and the group with obstructive sleep apnea (OSAG). The OSAG consisted of 21 patients with OSA of both genders, aged 20 to 60 years, diagnosed by baseline whole-night polysomnography held at Instituto do Sono de Santa Maria (ISSM), with AHI $\geq 5$ and $<30$ events/hour (mild and moderate apnea). AHI is classified as mild if 5-14 events/hour are present, moderate if $15-29$ events/hour are present, or severe if $\geq 30$ events/hour are present. ${ }^{5}$

The sample size calculation was performed based on the study by Lam et $\mathrm{al}^{16}$ evaluating the distance from the hyoid bone to the mandibular plane, by means of cephalometry in patients with OSA (AHI $\geq 5$ events/hour and $<30$ events/hour) and without OSA (AHI $<5$ events/hour). To obtain a significance level of $5 \%$ and power $(\beta)$ of $90 \%$, with $3.65 \mathrm{~mm}$ effect magnitude, this work has involved at least 20 subjects in each group (control and OSA), with a total number of 40 volunteers.
The CG consisted of 21 healthy subjects from the local community. Only subjects who did not have drowsiness were included, according to the Sleepiness Scale Epworth (ESE, score $<10$ points), ${ }^{17}$ with low probability of sleep apnea based on the Berlin Questionnaire $(\mathrm{BQ})^{18}$ and good sleep quality assessed by the Pittsburg Sleep Quality Index (PSQI$\mathrm{BR}$, score $\leq 5$ points), validated in Portuguese. ${ }^{19}$ Both groups were matched for gender and age.

We excluded from the study subjects with a history of facial and/or craniocervical trauma, presenting with musculoskeletal deformities, previous craniomandibular and/or cervical surgical procedures, using braces during the survey period, who underwent physical therapy for postural correction and/or speech therapy, using CPAP (Continuous Positive Airway Pressure) and/ or oral appliance for mandibular advancement and who had been submitted to nasal surgery or pharyngeal surgery (such as deviated septum correction, removal of tonsils and/or adenoids and/or uvulopalatopharyngoplasty). Moreover, we excluded subjects with any cognitive impairment that could affect the comprehension of the evaluations, who were unable to read or sign the Informed Consent (IC), diagnosed with heart disease or chronic obstructive pulmonary disease (COPD) and BMI above 30 or below $18.5 \mathrm{~kg} / \mathrm{m}^{2}$. We excluded subjects with BMI $>30 \mathrm{~kg} / \mathrm{m}^{2}$ to eliminate the influence of obesity on OSA and other study variables. ${ }^{3,20}$ We did not include subjects diagnosed by polysomnographic as severe basal level of OSA (AHI > 30 events/hour) in OSAG because in such cases, even if there was a postural component involved, the anatomical and/or intrinsic changes could have a greater impact in the context of the pathology, leading to a larger number of study biases. All volunteers agreed and signed the IC.

We invited the OSAG subjects to participate in the study by telephone, after previous selection by means of polysomnography analysis. The CG assessments occurred according to the availability of volunteers. The procedures were performed in the premises of ISSM, Clínica Imagem de Radiologia e Laboratório de Motricidade Orofacial do Departamento de Fonoaudiologia da UFSM and with the permission and consent of the respective managers between November 2014 and March 2015. The subjects completed a medical history form containing information such as age, body weight, and height. For the evaluation of craniofacial measurements, head posture, and air space measures, we applied the methods of cephalometry and photogrammetry.

The volunteers underwent a right lateral radiograph of the skull and cervical spine in normal standing position for cephalometric evaluation. To reproduce the natural head position, the participants kept staring at the reflection of their eyes in a mirror at a distance of one meter. ${ }^{21} \mathrm{~A}$ single trained examiner analyzed the radiographs, performing linear and angular measurements through manual and computerized methods (Software Cef X version 4.5.10, CDT, Cuiaba, Brazil).

The forward head posture was assessed manually through the $\mathrm{CPL} /$ Hor angle, which is formed by the intersection of CPL (Craniocervical Postural Line) and the horizontal line (CPL/Hor). ${ }^{21} \mathrm{CPL}$ touches the center points of the first six cervical vertebrae marked on the body. Individuals with a more forward head position angle featured $\mathrm{CPL} / \mathrm{Hor}<80^{\circ} .22$ 
Analyses of the adenoids, Rocabado and sleep apnea, were performed by means of computerized method, with the marking of the points made manually by a trained evaluator. In the adenoids analysis, the nasopharyngeal air space was evaluated, ${ }^{23}$ bringing together four cephalometric measurements to evaluate the nasopharyngeal region, following the standards described by Schulhof. ${ }^{23}$ Finally, an index was issued which represents the synthesis of all the factors, considering the presence or absence of adenoid hypertrophy (-Fig. 1).

The Rocabado analysis evaluates the spinal biomechanics, through the study of the head and hyoid bone position, the cervical spine inclination and the airway conditions. ${ }^{24}$ It comprises six cephalometric magnitudes; however, only three of them were used in this study, which verified the head and the hyoid bone posture. The cephalometric measures evaluated were: a) Craniocervical Angle (CVA); analysis of the cervical spine curvature and head posture in relation to the upper cervical posture (flexion/extension of the head), formed by the intersection of McGregor and Odontoid plans, classified as follows: normal head posture $96^{\circ}$ to $106^{\circ}$, head extension $<96^{\circ}$ and head bending $>106^{\circ 22}$; b) Distance $\mathrm{O}-\mathrm{A}$ : distance between the base of the occipital bone and the posterior arch of the atlas vertebra; it also evaluates the craniocervical posture, but in a linear fashion; c) Height $\mathrm{H}$ : distance from the body of the hyoid bone $(\mathrm{H})$ to the line formed by the antero-inferior points and retrognathia (RGn) of the third cervical vertebra (C3). It determines the spatial position of the hyoid bone and, consequently, the tongue posture. Measurements were taken according to the reference standards described by Rocabado ${ }^{24}$ (-Fig. 1).

In sleep apnea analysis, we analyzed craniofacial and upper air space measures, such as: Anterior cranial base (S-N); Jaw length (Ena-Enp); Mandibular length (Goc-Me); Soft palate length (Enp-P); Tongue length (TGL); Atlas-jaw distance (A-Enp); Hyoid bone-third cervical vertebra distance (H-C3); Distance between the hyoid bone and the mandibular plane (H-PM); Upper pharyngeal space (Upphw-PP1); Average posterolateral palatal space (PP2-PP2'); Average pharyngeal air space, located between the posterior pharyngeal wall and the lower limit of the uvula (Mpphw-Maphw); Posterior pharyngeal air space (PAS); Lower air space (LAS); Tongue height (TGH). Measurements were taken according to the reference standards described by Marques and Maniglia ${ }^{25}$ (-Fig. 1).

We also evaluated head and cervical spine posture by means of digital photography with photogrammetric analysis by the Postural Assessment Software (SAPO). ${ }^{22}$ The participants, with proper clothing, hair tied back, and barefoot, were photographed with a black background, a suspended plumb line next to the volunteers, and a rubber mat. The photographic records were obtained with the help of a 14.1 megapixel Sony (DSC-W350, Brazil) digital camera, set on a tripod positioned at a distance of $3 \mathrm{~m}$ and at $1.20 \mathrm{~m}$ height from the floor, right side view, in habitual posture. The same technique was used in cephalometry to reproduce the natural head position. ${ }^{21}$

The anatomical points were marked on the subject's body with white styrofoam balls previously prepared with doublesided tape for fixing on the skin. We used the tragus points, spinous process of the seventh cervical vertebra (C7) and orbicularis commissure for measuring the angles: Angle 1 (A1): formed between the tragus, the spinous process of $\mathrm{C7}$ (vertex) and the horizontal line, and angle 2 (A2): formed by the points scored in the spinous process of $\mathrm{C} 7$ (vertex), tragus and orbicularis commissure. ${ }^{22}$ The smaller the angle $A 1$, the higher the head anteriorization, and the greater the angle A2, the greater the head extension in the upper cervical spine. ${ }^{22}$

We used Statistica version 9.1 software for statistical analysis. We assessed data distribution by the Shapiro-Wilk Normality Test. The data were expressed as mean and standard deviation. For data comparison with normal distribution, we used the Student's t-Test or the unpaired MannWhitney $U$ Test, in cases of non-normality. We used the Chi-square or Fisher's Exact test to assess the associations between the categorical variables. We evaluated the correlations between the variables by Pearson (quantitative variables) or Spearman (quantitative or qualitative ordinal variables) Correlation Coefficient and classified according to the correlation of the magnitude scale proposed by Dancey and Reidy, ${ }^{26}$ where $r=0.10$ to 0.30 (weak); $r=0.40$ to 0.6 (moderate); $r=0.70$ to 1 (strong). We considered a $5 \%$ significance level.

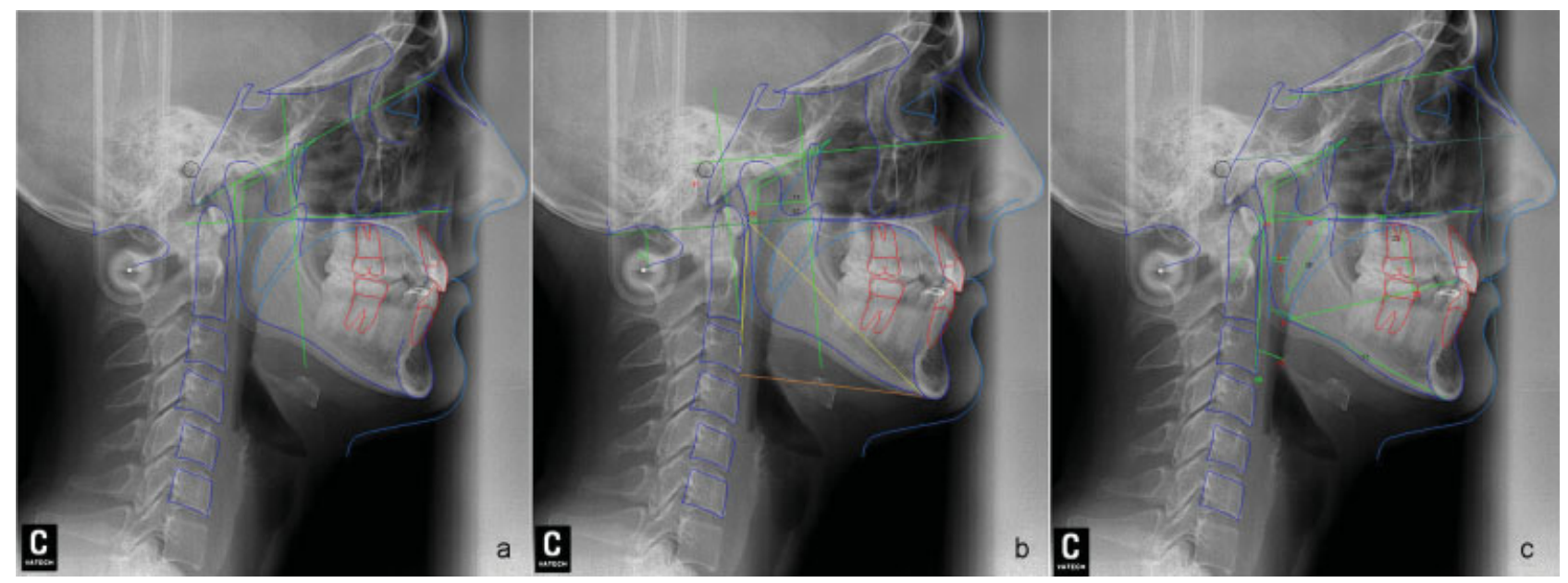

Fig. 1 Photographs of cephalometric standards used: (a) Adenoids analysis; (b) Rocabado Analysis; (c) Analysis of sleep apnea. 
192 Cervical Spine in Patients with Obstructive Sleep Apnea Piccin et al.

Table 1 Comparison of measurements photogrammetric and cephalometric and craniocervical posture obtained in groups with obstructive sleep apnea (OSAG) and control group (CG)

\begin{tabular}{|l|l|l|l|}
\hline & $\begin{array}{l}\text { AOSG } \\
\text { (mean and SD) }\end{array}$ & $\begin{array}{l}\text { GC } \\
\text { (mean and SD) }\end{array}$ & $p$-value \\
\hline Photogrammetry & & & \\
\hline A1 $\left(^{\circ}\right)$ & $45.42 \pm 4.98$ & $45.69 \pm 4.21$ & 0.855 \\
\hline A2 $\left(^{\circ}\right)$ & $153.23 \pm 6.53$ & $151.29 \pm 6.68$ & 0.347 \\
\hline Cephalometrics & & & \\
\hline CPL/Hor $\left({ }^{\circ}\right)^{\dagger}$ & $79.81 \pm 6.27$ & $82.29 \pm 11.19$ & 0.068 \\
\hline $\mathrm{CVA}\left({ }^{\circ}\right)$ & $96.00 \pm 4.97$ & $96.41 \pm 6.98$ & 0.825 \\
\hline Distance O-A (mm) & $14.12 \pm 3.98$ & $15.18 \pm 4.01$ & 0.396 \\
\hline Height $\mathrm{H}(\mathrm{mm})^{\dagger}$ & $-0.46 \pm 12.08$ & $-0.70 \pm 5.098$ & 0.346 \\
\hline
\end{tabular}

Abbreviations: $\mathrm{A} 1$, angle between the tragus, the spinous process of $\mathrm{C} 7$ (vertex) and the horizontal line; $\mathrm{A} 2$, angle between the points scored in the spinous process of C7 (vertex), tragus and orbicularis commissure; CG, control group; CPL/Hor, intersection of CPL (Craniocervical Postural Line) and the horizontal line; CVA, Angle Craniovertebral; DP, standard deviation; Distance O-A, distance between the base of the occipital bone and the posterior arch of the atlas vertebra; Height $\mathrm{H}$, distance from the body of the hyoid bone to the line formed by the antero-inferior points and retrognathia of the third cervical vertebra; OSAG, group with obstructive sleep apnea.

Student t Test; †U Test Mann-Whitney.

*Statistical significance: $\mathrm{p} \leq 0.05$.

\section{Results}

The groups were homogeneous regarding gender ( 12 men and 9 women in each group; $p=1.000)$, age (OSAG $=41.86 \pm 11.26$ years; $C G=41.19 \pm 11.20$ years; $p=0.831$ ), BMI (OSAG $\left.=25.65 \pm 2.46 \mathrm{~kg} / \mathrm{m}^{2} ; \mathrm{CG}=24.72 \pm 3.01 \mathrm{~kg} / \mathrm{m}^{2} ; p=0.268\right)$. The OSAG subjects showed AHI $=13.42 \pm 6.60$ events/hour (mild OSA), according to the whole-night polysomnography baseline report. In the cephalometric analysis of the adenoids, all subjects were within the normal range (index $=0$ ).

- Table 1 shows the values found in the comparative analysis of photogrammetry (A1 and A2) and cephalometry regarding the craniocervical posture in the groups with and without OSA. - Table 2 shows the values found in

Table 2 Comparison of measurements photogrammetric and cephalometric and upper air space obtained in groups with obstructive sleep apnea (OSAG) and control group (CG)

\begin{tabular}{|l|l|l|l|}
\hline & $\begin{array}{l}\text { OSAG } \\
\text { (mean and SD) }\end{array}$ & $\begin{array}{l}\text { CG } \\
\text { (mean and SD) }\end{array}$ & $p$-value \\
\hline S-N (mm) & $74.61 \pm 3.46$ & $74.53 \pm 4.31$ & 0.946 \\
\hline Ena-Enp (mm) & $58.22 \pm 3.55$ & $58.42 \pm 4.89$ & 0.882 \\
\hline Goc-Me (mm) & $74.97 \pm 5.34$ & $76.33 \pm 6.36$ & 0.459 \\
\hline A-Enp (mm) & $33.42 \pm 3.67$ & $34.12 \pm 4.04$ & 0.557 \\
\hline Upphw-PP1 (mm) & $22.05 \pm 5.61$ & $22.50 \pm 3.71$ & 0.756 \\
\hline PP2-PP2' (mm) & $10.72 \pm 4.03$ & $11.33 \pm 4.23$ & 0.635 \\
\hline Enp-P (mm) & $39.54 \pm 3.38$ & $38.10 \pm 6.09$ & 0.351 \\
\hline Mpphw-Maphw (mm) & $8.84 \pm 2.97$ & $10.95 \pm 3.34$ & $0.037^{*}$ \\
\hline PAS (mm) & $11.37 \pm 3.96$ & $11.93 \pm 3.64$ & 0.636 \\
\hline H-C3 (mm) & $33.62 \pm 4.40$ & $34.55 \pm 4.30$ & 0.494 \\
\hline H-PM (mm) & $18.22 \pm 6.31$ & $13.16 \pm 4.56$ & $0.005^{*}$ \\
\hline TGL (mm) & $72.86 \pm 6.27$ & $73.10 \pm 7.13$ & 0.907 \\
\hline TCH (mm) & $25.09 \pm 3.16$ & $23.29 \pm 6.02$ & 0.233 \\
\hline LAS (mm) & $11.14 \pm 5.07$ & $12.96 \pm 4.20$ & 0.211 \\
\hline
\end{tabular}

Abbreviations: A-Enp, Atlas-jaw distance; CG, control group; DP, standard deviation; Ena-Enp, Jaw length; Enp-P, Soft palate length; Goc-Me, Mmandibular length; $\mathrm{H}-\mathrm{C} 3$, Hyoid bone-third cervical vertebra distance; H-PM, Distance between the hyoid bone and the mandibular plane; Mpphw-Maphw, Average pharyngeal air space; PAS, Posterior pharyngeal air space; PP2-PP2 ', Average posterolateral palatal space; OSAG, group with obstructive sleep apnea; S-N, Anterior cranial base; TGL, Tongue length; TGH, Tongue height; LAS, Lower air space; Upphw-PP1, Upper pharyngeal space.

Student $t$ Test; †U Test Mann-Whitney.

* Statistical significance: $\mathrm{p} \leq 0.05$. 
cephalometric analyses regarding craniofacial measurements and upper air space in the groups with and without OSA, with significantly higher values of Mpphw-Maphw and reduced values for the distance H-PM in OSAG.

By correlating the cephalometric and photogrammetric variables with the $\mathrm{AHI}$, we observed a significant moderate positive correlation with angle A2 evaluated by photogrammetry, that is, the higher the AHI, the greater the head extension. There was a significant moderate negative correlation with the CPL/Hor and CVA angles, obtained by cephalometry. The higher the AHI, the lower the CPL/Hor angles, corresponding to greater head anteriorization and CVA, corresponding to the largest head extension. The remaining variables showed no significant correlation (-Table 3 ).

\section{Discussion}

The incidence of craniocervical postural changes in OSA subjects has been studied. ${ }^{25}$ Anatomically, the pharyngeal airway, which is the site of obstruction in OSA, is surrounded by soft tissue and the jaw, depending not only on the tissue volume, but also on the size and the mandibular position. Even more remarkable is the fact that the jaw can move in the anteroposterior direction, producing changes in craniocervical angles. ${ }^{27}$ Thus, the airway dimensions and structures seem to be affected by head posture and inclination and body posture when evaluated by Cephalometry. ${ }^{12,13}$ However, in this study, we found no differences between the groups regarding craniocervical posture, because both groups had normal head posture when we evaluated the craniovertebral and CPL/Hor angles, reflecting in the subjects' normal head posture.

Craniofacial measures, such as increased dimensions of pharyngeal soft tissue, increased hyoid distance, increased tongue and soft palate thickness, and narrowing of the upper pharynx, oropharynx and hypopharynx air space, may be important risk factors for the development of OSA. ${ }^{3,25}$ OSA subjects may also present reduced length of the midface, inferiorly positioned hyoid bone, and smaller airways. ${ }^{28}$ The determining factors in the collapse of the upper airway are multiple, the airway anatomy being only one of them. ${ }^{29}$

Table 3 Correlations between the apnea/hypopnea index (AHI) and cephalometric and photogrammetric variables

\begin{tabular}{|l|l|l|}
\hline & AHI & \\
\hline & Coefficient $\mathrm{r}$ & $p$-value \\
\hline A2 $\left(^{\circ}\right)$ & 0.66 & $0.001^{*}$ \\
\hline CPL/Hor $\left(^{\circ}\right)$ & -0.45 & $0.040^{*}$ \\
\hline CVA $\left(^{\circ}\right)$ & -0.51 & $0.017^{*}$ \\
\hline
\end{tabular}

Abbreviations: AHI, apnea/hypopnea index; A2, flexion/extension of the head by means of photogrammetry; $\mathrm{CPL} / \mathrm{Hor}$, forward head through cephalometry; CVA, flexion/extension of the head through the Cephalometry.

Pearson correlation coefficient.

* Statistical significance: $\mathrm{p} \leq 0.05$.
Skeletal measures influence the upper airway dimensions. The main parameters of the pharynx are the posterior air space, that is, the distance between the posterior pharyngeal wall and the tongue base or soft palate, and may be divided into upper, middle, and lower pharyngeal space. In this study, middle pharyngeal space values (between posterior pharyngeal wall and the lower limit of the uvula) of the OSAG were significantly lower when compared with the control group $(p=0.037)$. This result is in accordance with a study ${ }^{3}$ in which a reduction in the posterior airway space was observed in OSA subjects, and this characteristic is considered to be a risk factor for the occurrence of OSA.

Regarding the distance from the hyoid bone to the mandibular plane (MP-H), higher values were found in the OSAG when compared with CG. This reflects a lower position of the hyoid bone, which, according to studies, ${ }^{25,28,30}$ may be associated with the presence of OSA. The hyoid bone position impacts the tongue shape and position, affecting the airway patency in the hypopharynx. ${ }^{31}$ Therefore, attention should be paid to the increased distance from the hyoid bone, because as the tongue muscles are partly anchored to the hyoid bone, its height can influence the relationship of soft tissues in the oropharynx, facilitating the airway collapse during sleep. ${ }^{30}$

Increased severity of OSA, verified by AHI, correlated with an increase in the angle $\mathrm{A} 2$, obtained by photogrammetry, and the reduction of the $\mathrm{CPL} / \mathrm{Hor}$ angles and CVA obtained by cephalometry. These results show the influence of head posture in the presence of OSA, and head hyperextension and anteriorization correlated with the severity of OSA. Another study found that only the measures of the distance between the mandibular plane and the hyoid bone, the distance between the posterior nasal spine and the soft palate, and the cervical and abdominal circumferences correlated with the severity of OSA (AHI) in patients aged $\geq 40$ and $<60$ years. $^{32}$ In another study evaluating 96 subjects, the only cephalometric variable that showed a statistically significant correlation with AHI was the linear distance perpendicular from the hyoid bone to the mandibular plane, ${ }^{30}$ whose measure in this study was higher in the OSAG, but did not correlated with the AHI. This may be due to the larger size and different composition of the study sample according to the classification of the severity of apnea, with 11 subjects presenting with snoring, 20 subjects with mild apnea, 26 with moderate apnea, and 39 with severe apnea. $^{30}$

Patients with sleep-disordered breathing (SDB) typically have several physiological characteristics that may explain the disorder. However, several non-anatomical factors may be responsible for this condition. During sleep, the masticatory muscle activity and the tongue play an important role in SDB. In AOS, the influence of the force of gravity on the mandible, especially in the supine position, combined with muscle hypotonia of the tongue and masticatory muscles results in a further displacement of the jaw and tongue, thus narrowing the oropharynx and increasing the upper airway resistance. ${ }^{33}$ The correlation between the severity of OSA with the head anteriorization is justified by the fact that this approach produces a posterior displacement of the mandibular condyle, ${ }^{22}$ which may lead to a reduction in the upper airspace. 
The hypothesis that anatomical factors are involved in the etiology of OSA has extensive support in the literature. Therefore, it is important to know the predominant anatomic alterations in individuals with apnea, so that the professionals can identify the risk factors and refer the patient to a specialist to carry out specific tests, such as polysomnography, considered the gold standard for diagnosis of OSA. This will contribute to the early diagnosis, avoiding the consequent serious sequelae. The present results are in accordance with the hypothesis of this study, where differences were found in craniofacial morphology of OSA subjects compared with healthy subjects, suggesting the influence of craniocervical posture in the severity of OSA. However, it is important to note that, although there may be a recognizable cephalometric predisposition to SDB, this is just one of the many aspects involved in the pathophysiology of OSA. These findings are valuable for clinical practice, as the global perception of the patient is a major challenge for health professionals aiming to perform a careful evaluation and to propose an appropriate treatment program. Future studies should be conducted to provide more information on the collapsibility of the upper airways.

\section{Conclusions}

The subjects in the group of mild and moderate OSA feature changes in craniofacial morphology, with shorter intermediate pharyngeal space and greater distance from the hyoid bone to the mandibular plane, as compared with healthy subjects, suggesting a relationship between craniocervical posture and OSA. Moreover, in OSA subjects, head hyperextension and anteriorization correlated with the severity of OSA, analyzed by the AHI.

\section{References}

1 Davatz AF, Andrade HLI, Melo IVP, et al. Síndromes da apneia e hipopnéia obstrutiva do sono: revisão da literatura. Rev Eletr Acerv Sau 2012;1:27-33

2 Arya D, Tripathi A, Singh SV, Tripathi S, Nagar A, Mishra A. A pilot study to evaluate posttreatment cephalometric changes in subjects with OSA. J Prosthet Dent 2010;103(3):170-177

3 Thapa MA, Jayan BB, Nehra LCK, Agarwal MSS, Patrikar S, Brattacharya $C D$. Pharyngeal airway analysis in obese and non-obese patients with obstructive sleep apnea syndrome. Med J Armed Forces India 2014:1-7

4 Eckert DJ, White DP, Jordan AS, Malhotra A, Wellman A. Defining phenotypic causes of obstructive sleep apnea. Identification of novel therapeutic targets. Am J Respir Crit Care Med 2013;188(8): 996-1004

5 American Academy of Sleep Medicine (AASM). International classification of sleep disorders. 2nd ed. Diagnostic and coding manual. Westchester, IL: American Academy of Sleep Medicine; 2005

6 Landmann N, Kuhn M, Piosczyk H, et al. The reorganisation of memory during sleep. Sleep Med Rev 2014;18(6):531-541

7 Villanueva P, Valenzuela S, Santander H, Zúñiga C, Ravera MJ, Miralles R. Efecto de la postura de cabeza em mediciones de la vía aérea. Rev CEFAC 2004;6:44-48

8 Maschtakow PSL, Tanaka JLO, da Rocha JC, et al. Cephalometric analysis for the diagnosis of sleep apnea: a comparative study between reference values and measurements obtained for Brazilian subjects. Dental Press J Orthod 2013;18(3):143-149

9 Salles C, Campos PSF, de Andrade NA, Daltro C. Obstructive sleep apnea and hypopnea syndrome: cephalometric analysis. Braz J Otorhinolaryngol 2005;71(3):369-372

$10 \mathrm{Ryu} \mathrm{HH}$, Kim CH, Cheon SM, et al. The usefulness of cephalometric measurement as a diagnostic tool for obstructive sleep apnea syndrome: a retrospective study. Oral Surg Oral Med Oral Pathol Oral Radiol 2015;119(1):20-31

11 Bharadwaj R, Ravikumar A, Krishnaswamy NR. Evaluation of craniofacial morphology in patients with obstructive sleep apnea using lateral cephalometry and dynamic MRI. Indian J Dent Res 2011;22(6):739-748

12 Muto T, Takeda S, Kanazawa M, Yamazaki A, Fujiwara Y, Mizoguchi I. The effect of head posture on the pharyngeal airway space (PAS). Int J Oral Maxillofac Surg 2002;31(6):579-583

13 Miyamoto K, Ozbek MM, Lowe AA, Fleetham JA. Effect of body position on tongue posture in awake patients with obstructive sleep apnoea. Thorax 1997;52(3):255-259

14 Pracharktam N, Hans MG, Strohl KP, Redline S. Upright and supine cephalometric evaluation of obstructive sleep apnea syndrome and snoring subjects. Angle Orthod 1994;64(1):63-73

15 Souza JA, Pasinato F, Basso D, Correa ECR, Silva AMT. Biophotogrammetry: reliability of measurements obtained with a posture assessment software (SAPO). Rev Bras Cineantropom Desempenho Hum. 2011;13:299-305

16 Lam B, Ooi CG, Peh WC, et al. Computed tomographic evaluation of the role of craniofacial and upper airway morphology in obstructive sleep apnea in Chinese. Respir Med 2004;98(4): 301-307

17 Johns MW. A new method for measuring daytime sleepiness: the Epworth sleepiness scale. Sleep 1991;14(6):540-545

18 Netzer NC, Stoohs RA, Netzer CM, Clark K, Strohl KP. Using the Berlin Questionnaire to identify patients at risk for the sleep apnea syndrome. Ann Intern Med 1999;131(7):485-491

19 Bertolazi AN, Fagondes SC, Hoff LS, et al. Validation of the Brazilian Portuguese version of the Pittsburgh Sleep Quality Index. Sleep Med 2011;12(1):70-75

20 Peppard PE, Young T, Barnet JH, Palta M, Hagen EW, Hla KM. Increased prevalence of sleep-disordered breathing in adults. Am J Epidemiol 2013;177(9):1006-1014

21 Visscher CM, De Boer W, Lobbezoo F, Habets LL, Naeije M. Is there a relationship between head posture and craniomandibular pain? J Oral Rehabil 2002;29(11):1030-1036

22 Weber P, Corrêa ECR, Milanesi JM, Soares JC, Trevisan ME. Craniocervical posture: cephalometric and biophotogrammetric analysis. Braz J Oral Sci 2012;11:416-421

23 Schulhof RJ. Consideration of airway in orthodontics. J Clin Orthod 1978;12(6):440-444

24 Rocabado M. Biomechanical relationship of the cranial, cervical, and hyoid regions. J Craniomandibular Pract 1983;1(3):61-66

25 Marques CG, Maniglia JV. Estudo cefalográfico de indivíduos com Síndrome da Apneia Obstrutiva do Sono: revisão de literatura. Arq Ciênc Saúde 2005;12(4):206-212

26 Dancey C, Reidy J. Estatística Sem Matemática para Psicologia: Usando SPSS para Windows. Porto Alegre, Artmed.2006

27 Muto T, Yamazaki A, Takeda S, et al. Relationship between the pharyngeal airway space and craniofacial morphology, taking into account head posture. Int J Oral Maxillofac Surg 2006;35(2): 132-136

28 Gungor AY, Turkkahraman H, Yilmaz HH, Yariktas M. Cephalometric comparison of obstructive sleep apnea patients and healthy controls. Eur J Dent 2013;7(1):48-54

29 Sforza E, Bacon W, Weiss T, Thibault A, Petiau C, Krieger J. Upper airway collapsibility and cephalometric variables in patients with obstructive sleep apnea. Am J Respir Crit Care Med 2000;161(2 Pt 1):347-352 
30 Silva VG, Pinheiro LAM, Silveira PL, et al. Correlation between cephalometric data and severity of sleep apnea. Braz J Otorhinolaryngol 2014;80(3):191-195

31 Yucel A, Unlu M, Haktanir A, Acar M, Fidan F. Evaluation of the upper airway cross-sectional area changes in different degrees of severity of obstructive sleep apnea syndrome: cephalometric and dynamic CT study. AJNR Am J Neuroradiol 2005;26(10):2624-2629
32 Borges PdeT, Silva BB, Moita Neto JM, Borges NE, Li LM. Cephalometric and anthropometric data of obstructive apnea in different age groups. Braz J Otorhinolaryngol 2015;81(1):79-84

33 Balasubramaniam R, Klasser GD, Cistulli PA, Lavigne GJ. The Link between Sleep Bruxism. Sleep Disordered Breathing and Temporomandibular Disorders: An Evidence-based Review JDSM 2014; $1: 27-37$ 